\title{
On the safety and efficacy of human patient stem cell transplantation therapy
}

\begin{abstract}
Although stem cell therapy is very promising, so far, there are insufficient clinical trials reported. Therefore, the safety and efficacy of stem cell transplantation are still not confirmed clinically. Here, we reported approximately 9,000 patient cases treated with human fetal neural stem cells, human mesenchymal stem cells and human adipose stem cells for various human diseases. By follow-up visits, the efficacies of the treatments were confirmed. These data vigorously demonstrated the safety and effectiveness of stem cell therapy for patients, and provided critical evidence for the great promises of the therapeutic applications of human stem cells.
\end{abstract}

Keywords: stem cell therapy, human fetal neural stem cells, human mesenchymal stem cells, human adipose stem cells
Volume 2 Issue 3 - 2017

\author{
Taihua Wang, ${ }^{1,2}$ Gang Zhang ${ }^{1,2}$ \\ IInterventional Hospital of Shandong Red Cross Society, China \\ ${ }^{2}$ Cell Biotechnology Co., Ltd, China \\ These authors contributed equally to this work
}

\begin{abstract}
Correspondence: Taihua Wang, Interventional Hospital of Shandong Red Cross Society, Jinan, Shandong Province, China, 250000,Email drwangtaihua@hotmail.com

Gang Zhang, Interventional Hospital of Shandong Red Cross Society, Jinan, Shandong Province, China, 250000,

Email sdzbzhanggang@।63.com; gang_zhang@stemceltech.com
\end{abstract}

Received: April 05, 2017| Published: May 10, 2017

Abbreviations: HFNSC, human fetal neural stem cell; HASC, human adipose stem cell; HMSC, human mesenchymal stem cell

\section{Background}

It had been a long-time controversy for stem cell therapy about its safety and efficacies. ${ }^{1-3}$ The main concerns included the tumor formation and immune rejection. ${ }^{4}$ So far, the main data of stem cell therapy were obtained from animal models, such as mice, ${ }^{5}$ rats $^{6,7}$ and monkeys ${ }^{8}$ etc. Among these investigations, most of the allogenic stem cell transplantations were performed into immuno-deficient animal models to avoid the rejections of transplanted stem cells. ${ }^{5,6,8}$ These immuno-deficient animal models are currently widely used. Although these models can allow the transplanted stem cells to integrate into the hosts, the lack of normal immune system failed to vigorously evaluate their tumor formation potentials. Hence, the safety issues of stem cell therapy could not be demonstrated reliably. ${ }^{4}$ Therefore, the huge gap between laboratory investigations and clinical stem cell therapies still existed.

\section{Statement of ethical approval}

The treatments for the patients and the use of human stem cells were approved by the Ethics Committee of Interventional Hospital of Shandong Red Cross Society (Shengjieyi 2003, No.26) in compliance with Helsinki Declaration. The Ethics Committee of Interventional Hospital of Shandong Red Cross Society approved this clinical study and treatments. The participants provided their written confirmed consent to participate the clinical study and treatments. The Ethics Committee of Interventional Hospital of Shandong Red Cross Society approved this consent procedure. All the treatments for the patients and use of human stem cells were performed in accordance with the guidelines established in Interventional Hospital of Shandong Red Cross Society approved by the Ethics Committee. After traditional treatments, these patients could not improve their physical conditions further. Therefore, they agreed to try the stem cell therapy in our hospital. The stem cells used in these clinical treatments included human fetal neural stem cells (HFNSC) from aborted fetuses, human mesenchymal stem cells (HMSC) and human adipose stem cells (HASC). All these stem cells were isolated and proliferated with the written confirmed consent of the patients and their parents.

\section{Clinical stem cell transplantation cases}

Due to the lack of clinical data of human stem cell therapy, it is widely believed that autologous and/or allogeneic stem cell transplantation into the patients could result in tumor formation and immune rejection. These dilemma and controversies troubled the basic stem cell scientists and clinical physicians greatly. During the past decade, our hospital treated 8,834 volunteered patients with stem cell therapy. These patients suffered various diseases and injuries, including Parkinson disease, brain trauma, spinal cord injury, diabetes, etc. Although these patients were firstly treated traditionally, they could not improve their physical conditions further. Subsequently, they desired to get more efficient therapy to improve their physical conditions. Therefore, they volunteered to try stem cell therapy according to their different disorders in our hospital. The stem cells employed for the patients included HFNSCs, HMSCs and HASCs. To date, no tumor formation was observed. The obvious effective rates of the treatments were about $40-95 \%$, and the effectiveness rates were about $50-95 \%$, respectively. In an astonishing patient case, the patient's spinal cord was severely injured in a car accident, after traditional treatments, he was treated with10 times of HFNSCs transplantation. ${ }^{9}$ Gradually, he recovered very well and even could ride motorcycle and work as an courier. Here, for the first time in the world, we reported a huge number of patients treated with different stem cells. These data demonstrated that human stem cell therapy is safe and effective. This important discovery overturned the long-existed controversies about stem cell therapy for the concerns of tumor formation and immune rejection. Based on the patient follow-up visits, the effectiveness of stem cell therapy was showed in Table 1 (this table is original for this article). 
Table I The effective rates of the stem cell transplantation therapy for different diseases based on the patient follow-up visits.

\begin{tabular}{|c|c|c|c|c|c|}
\hline Kinds of diseases & $\begin{array}{l}\text { Patient } \\
\text { number }\end{array}$ & Stem cells & $\begin{array}{l}\text { Effective } \\
\text { rate }\end{array}$ & $\begin{array}{l}\text { Obvious effect } \\
\text { rate }\end{array}$ & $\begin{array}{l}\text { Ineffective } \\
\text { rate }\end{array}$ \\
\hline Brain trauma and stroke Sequelae & 1280 & HFNSCs & $78 \%$ & $65 \%$ & $22 \%$ \\
\hline Cerebral palsy & 1295 & HFNSCs & $85 \%$ & $76 \%$ & $15 \%$ \\
\hline Down's syndrome & 300 & HFNSCs & $95 \%$ & $95 \%$ & $5 \%$ \\
\hline Cerebellar atrophy & 980 & HFNSCs & $70 \%$ & $57 \%$ & $30 \%$ \\
\hline Alzheimer disease, brain Atrophy & 553 & HFNSCs & $78 \%$ & $65 \%$ & $22 \%$ \\
\hline Myasthenia gravis & 6 & HFNSCs & $50 \%$ & $40 \%$ & $50 \%$ \\
\hline Optic atrophy & 108 & HFNSCs & $70 \%$ & $65 \%$ & $30 \%$ \\
\hline Parkinson disease & 712 & HFNSCs & $74 \%$ & $70 \%$ & $26 \%$ \\
\hline Multiple system atrophy & 181 & HFNSCs & $68 \%$ & $60 \%$ & $32 \%$ \\
\hline Multiple sclerosis & 62 & HFNSCs & $57 \%$ & $45 \%$ & $43 \%$ \\
\hline Spinal cord injury & 1245 & HFNSCs & $80 \%$ & $75 \%$ & $20 \%$ \\
\hline Diabetes & 944 & HMSCs + HASCs & $79 \%$ & $70 \%$ & $21 \%$ \\
\hline Motor neuron diseases & 184 & HFNSCs & $79 \%$ & $65 \%$ & $21 \%$ \\
\hline Liver cirrhosis & 148 & HMSCs + HASCs & $85 \%$ & $85 \%$ & $15 \%$ \\
\hline Chronic nephrosis & 126 & HMSCs + HASCs & $85 \%$ & $85 \%$ & $15 \%$ \\
\hline Cardio-cerebral-vascular disease & 704 & HMSCs + HFNSCs & $89 \%$ & $80 \%$ & $11 \%$ \\
\hline Plant human patient & 6 & HFNSCs & $75 \%$ & $70 \%$ & $25 \%$ \\
\hline
\end{tabular}

\section{Conclusion}

Although clinical stem cell therapy for patients is very promising, the lack of vigorous animal models to assess the tumor formation and immune rejection of transplanted stem cells ${ }^{5-8}$ leads to a dilemma with controversies. Recently, a novel animal model, "Mouse Clone Model", was proposed, ${ }^{4}$ yet, it still need a long time to be proved world-widely. During the past decade, we treated 8,834 patients with HFNSCs, HMSCs and HASCs. Many patients improved their physical conditions significantly. Most importantly, no tumor-formation was observed in any patients. These data vigorously proved that stem cell transplantation is safe and effective for curing different human diseases. These data of stem cell therapy for 8,834 cases provided strong evidence for the safety and efficacy of clinical stem cells therapy and laid important foundations for regenerative medicine.

\section{Declarations}

\section{Ethical Approval and Consent to participate}

Described in Statement of ethical approval section.

\section{Consent for publication}

All the participated patients were consent for the publication of this work.

\section{Availability of supporting data}

The datasets generated and/or analysed during the current study are not publicly available due to the protection of the confidential information of the participated patients but are available from the corresponding author on reasonable request.

\section{Competing interests}

The authors declare they have no competing interests.

\section{Authors contributions}

T W instructed and performed the clinical part of the work, GZ instructed and performed the experiment part of the work. Both authors discussed, wrote, read and approved the final manuscripts.

\section{Acknowledgements}

The authors wish to thank the technicians and nurses in our laboratory and hospital for their help and caring of the patients during the treatments and experiments.

\section{Conflict of interest}

The author declares no conflict of interest.

\section{References}

1. Freed CR, Greene PE, Breeze RE, et al. Transplantation of embryonic dopamine neurons for severe Parkinson's disease. $N$ Engl JMed. 2001;344(10):710-719.

2. Hagell P, Piccini P, Björklund A, et al. Dyskinesias following neural transplantation in Parkinson's disease. Nat Neurosci. 2002;5(7):627628.

3. Olanow CW, Goetz CG, Kordower JH, et al. A double-blind controlled trial of bilateral fetal nigral transplantation in Parkinson's disease. Ann Neurol. 2003;54(3):403-414.

4. Zhang G, Zhang Y. "Mouse Clone Model" for evaluating the immunogenicity and tumorigenicity of pluripotent stem cells. Stem Cell Res Ther. $2015 ; 6: 255$. 
5. Gussoni E, Soneoka Y, Strickland CD, et al. Dystrophin expression in the mdx mouse restored by stem cell transplantation. Nature. 1999;401(6751):390-394.

6. Bjorklund LM, Sanchez Pernaute R, Chung S, et al. Embryonic stem cells develop into functional dopaminergic neurons after transplantation in a Parkinson rat model. Proc Natl Acad Sci USA. 2002;99(4):2344-2349.

7. Jensen MB, Han DY, Sawaf AA, et al. Behavioral outcome measures used for human neural stem cell transplantation in rat stroke models. Neurol Int. 2011;3(2):e10.
8. Hermann BP, Sukhwani M, Winkler F, et al. Spermatogonial stem cell transplantation into rhesus testes regenerates spermatogenesis producing functional sperm. Cell Stem Cell. 2012;11(5):715-726.

9. Wang T, Li R, Zhang G. Significant physical improvement of spinal cord injured patients after neural stem cell transplantation. AdvTissue Eng Regen Med. 2017;2(1):00018. 